\title{
TAXA DE JUROS: \\ COMPORTAMENTO, DETERMINAÇÃO \\ E IMPLICAÇÕES PARA A \\ ECONOMIA BRASILEIRA*
}

\author{
Jabr H. D. Omar ${ }^{* *}$
}

\begin{abstract}
RESUMO O objetivo principal deste trabalho é analisar o comportamento e os fatores determinantes da taxa de juros e seus efeitos sobre a condução da política macroeconômica no Brasil desde julho de 1994. Assim, tenta responder às seguintes questões: Por que as taxas reais de juros são altas? Quais são as forças que realmente as determinam? Quais são as implicações para a economia, se essas permanecerem altas? O que pode ser feito para reduzir os seus níveis atuais? Os resultados obtidos mostraram que as causas principais das altas taxas de juros se encontram no âmbito de reduzir e controlar a taxa de inflação, na vulnerabilidade do setor externo, na alta dívida pública e na estrutura de mercado bancário. Inclusive, constatou-se que as altas taxas de juros têm efeitos perversos e não condizentes, tanto para o crescimento como para a estabilidade econômica. Para diminuí-las foram sugeridas recomendações no campo da política monetária, política fiscal, setor externo e política de concorrência.
\end{abstract}

Palavras-chave: taxa de juros; setor externo; dívida pública

Código JEL: E43

\section{INTEREST RATE: ITS BEHAVIOR, DETERMINATION, AND IMPLICATIONS FOR THE BRAZILIAN ECONOMY}

ABSTRACT The main purpose of this paper is to analyze the behavior and the factors that determine the interest rate and its impact on conducting the macroeco-

* Artigo recebido em 26 de agosto de 2005 e aprovado em 26 de agosto de 2008.

** Professor titular da UCPel e da UFPel. Ph. D. em Economia pela McGILL Univertsity/Montreal, Canadá, e-mail: maisar@via-rs.net. O autor agradece ao professor Antonio Carlos Fraquelli a leitura do texto e as importantes contribuições. Agradece também ao professor Dary Neto as sugestões e o apoio técnico. 
nomic policy in Brazil through the period of July 1994 to August 2004. Thus, the article attempts to address answers for three main questions: why real interest rates are high in Brazil and what are the main forces that stand behind their determination? What are the economic implications if real interest rates remain high? What can be done to reduce real interest rates from their present levels? Results obtained show that the main reasons for high real interest rates were found to be in: reducing and controlling the high rates of inflation, vulnerability of the foreign sector, high public debt, and the market structure of the banking sector. More over, it was argued that high real interest rates have perverse effects for economic growth and economic stability. To reduce interest rates from their present levels, certain recommendations were suggested with regard to monetary policy, fiscal policy, foreign sector, and competitive policy in the banking system.

Key words: interest rate; foreign sector; public debt 


\section{INTRODUÇÃO}

A taxa de juros pode ser definida como o preço do uso do dinheiro para um determinado período de tempo. Porém, enquanto a taxa de juros for um preço, seu impacto na economia não é limitado para o seu próprio mercado. Assim, enquanto uma mudança no preço da laranja afeta o mercado desse produto, e uma mudança na taxa do salário atinge o mercado da mão-deobra, a mudança na taxa de juros tem implicações muito mais sérias para a economia, porque afeta uma grande variedade de decisões, desde as despesas diárias dos consumidores até decisões críticas de investimentos que afetam a estrutura econômica de um determinado país. Conseqüentemente, a taxa de juros desempenha um papel chave na tomada de decisões econômicas, já que interfere nos preços e nos custos de todos os setores da economia. É importante notar que há estreitas relações entre a taxa de juros e as variáveis econômica chave como: a inflação, o desemprego, a taxa de câmbio, os fluxos de capital, a estrutura da balança de pagamentos e o nível da dívida externa e interna. Um aumento na taxa de juros afetará investimento e consumo negativamente e, assim, interferirá no crescimento da economia. Em um país com dívida pública alta, o impacto da alta taxa de juros se ligará diretamente ao aumento da dívida pública e afetará severamente a capacidade do governo para financiar seus projetos de investimento e cumprimento de seus programas econômicos e sociais. Em uma economia aberta, com mercados mundiais altamente integrados, qualquer mudança na taxa de juros poderia produzir movimentos nos fluxos de capital estrangeiro de importantes volumes que poderiam complicar a condução da política macroeconômica e gerar instabilidade econômica.

$\mathrm{Na}$ atualidade, no Brasil, não causa surpresa ler nos jornais ou ouvir em rádio ou televisão reclamações diárias sobre altas taxas de juros praticadas pelo setor financeiro, visto que essas taxas, na forma nominal ou real, estão entre as mais altas no mundo. Segundo dados publicados pelo Banco Central Europeu, o nível geral das taxas de juros praticadas para o setor privado, na área do euro foi em torno de 4 a 8\% ao ano, em agosto de 2004. No Brasil, as taxas de juros anuais para o mesmo período e mesmo setor alcançaram um patamar entre 40 e 50\% ao ano, e, em certas categorias (cheque especial, por exemplo) esta alcançou 140\%. Isso significa que para um em- 
préstimo de $\mathrm{R} \$ 10.000,00$ deverão ser pagos $\mathrm{R} \$ 24.000,00$ no período de um ano. É um fenômeno preocupante.

Desde julho de 1994, as autoridades brasileiras usaram taxas de juros altas como um instrumento para alcançar dois objetivos principais: combater a inflação restringindo a demanda agregada e servir como instrumento para atrair capital externo com a finalidade de cobrir o déficit da conta-corrente na balança de pagamentos e aumentar as reservas internacionais. A mesma política, porém, produziu efeitos negativos sobre o investimento, aumentando não apenas o déficit do governo e a dívida pública, como também a vulnerabilidade externa da economia brasileira.

O objetivo principal deste trabalho é analisar o comportamento e os fatores determinantes da taxa de juros e seus efeitos sobre a condução da política macroeconômica no Brasil, no período de 1994 a 2004. Assim, tenta responder às seguintes questões: As taxas de juros reais no Brasil são altas ou não? Por que as taxas de juros são altas? Quais são as forças que realmente as determinam? Quais são as implicações para a economia, se essas permanecerem altas? $\mathrm{O}$ que pode ser feito para reduzir os seus níveis atuais?

A importância deste trabalho reside no fato de que, em face do quadro recessivo que a economia brasileira vem enfrentando nos últimos anos, diminuir as taxas de juros reais deve ser um dos objetivos principais da política econômica brasileira. Nesse contexto, torna-se necessário e importante encontrar respostas para as perguntas apresentadas.

As modalidades das taxas de juros utilizadas neste trabalho foram classificadas da seguinte forma: para o setor empresarial (pessoa jurídica), taxas de juros praticadas para desconto de duplicatas e taxas de juros sobre capital de giro; para o consumidor (pessoa física), taxas de juros sobre crédito pessoal (CDC) e taxas de juros sobre cheque especial. Para taxa de captação do sistema financeiro foi utilizada a taxa média de Certificados de Depósitos Bancários (CDBs) emitidos pelo sistema bancário. Para a comparação da taxa de juros no Brasil em relação às taxas praticadas no mundo foram utilizadas as seguintes: para o Brasil, taxa de juros paga sobre títulos da dívida pública do governo brasileiro (Selic); para o mundo, London Interbank Offer Rate (Libor), a mais conhecida taxa de juros aplicada sobre empréstimo de seis meses no mercado internacional, e Federal Funds, que é a taxa básica de juros nos Estados Unidos. Como indicadores da inflação, foram utilizados o 
Índice Geral de Preços do Mercado (IGP-M), da FGV, e o Índice Geral de Preço ao Consumidor (IPC), no Brasil e nos Estados Unidos. A análise empírica da taxa de juros foi realizada utilizando-se dados mensais anualizados de julho de 1994 a agosto de 2004.

\section{MAGNITUDE E COMPORTAMENTO DAS TAXAS DE JUROS NO BRASIL}

Os dados sobre as taxas de juros reais praticadas no Brasil e no mercado internacional, no período de 1995 a 2004, são apresentados na tabela 1 e no gráfico 1.

Examinando-se esses dados, observa-se que as taxas de juros praticadas no Brasil estão muito altas em comparação com aquelas praticadas no mercado internacional. Assim, enquanto o nível geral das taxas de juros reais se situa entre $-4,0 \%$ e $1,8 \%$ ao ano no caso de Libor, a taxa de juros paga sobre os títulos da dívida pública (Selic) ficou entre 1,9\% e 17,3\% ao ano. Nos últimos 10 anos, a média anual das taxas de juros reais sobre Libor e Federal Funds foi quase zero: $0,2 \%$ e $-0,2 \%$, respectivamente, e a taxa Selic ficou em torno de $11,1 \%$. Na condição de estabilidade cambial, isso implica que uma aplicação no Brasil rende, em termos reais, 11 vezes mais do que uma apli-

Tabela 1: Evolução e média da taxa de juros real (1)

\begin{tabular}{lccc}
\hline Ano & Selic & Libor & Federal Funds (2) \\
\hline 1995 & 01,5 & 1,8 & 1,6 \\
\hline 1996 & 13,7 & 0,8 & 1,2 \\
\hline 1997 & 24,0 & 2,1 & 1,9 \\
\hline 1998 & 17,3 & 3,0 & 2,9 \\
\hline 1999 & 07,1 & 1,9 & 1,4 \\
\hline 2000 & 11,3 & 1,0 & 0,6 \\
\hline 2001 & 11,2 & $-1,3$ & $-2,2$ \\
\hline 2002 & 10,2 & $-2,9$ & $-3,1$ \\
\hline 2003 & 04,1 & $-2,2$ & $-2,0$ \\
\hline Média 95-00 & 01,4 & $-4,0$ & $-4,3$ \\
\hline Média 01-04 & 12,5 & 1,8 & 1,6 \\
\hline Média 95-04 & 09,1 & $-2,6$ & $-2,9$ \\
\hline
\end{tabular}

Fonte: Conjuntura Econômica. Rio de Janeiro: FGV, n. 11, nov. 2004.

(1) Os valores foram deflacionados pelo IPC-FGV no Brasil e IPC nos Estados Unidos.

(2) Federal Funds - Taxa básica de juros nos Estados Unidos.

(3) Média mensal anualizada até agosto. 
Gráfico 1: Evolução das taxas reais de juros

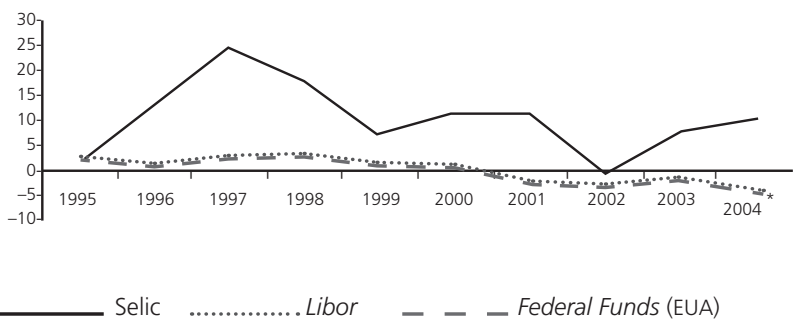

Fonte: Tabela 1

cação no mercado internacional. Nota-se que esse diferencial sempre foi mantido e parece ter-se tornado uma meta da política de juros, sejam as taxas de juros externas positivas (período 1995-2000) ou negativas (período 2001-2004).

$\mathrm{O}$ quadro se torna mais sério, verificando-se as taxas de juros praticadas nos empréstimos ao setor privado. Os gráficos 2 e 3 e as tabelas 3 e 4 mostram a evolução das taxas de juros reais para o setor privado e a taxa de captação no setor bancário.

Apesar de as tabelas serem auto-explicativas, examinando-se os dados apresentados, as seguintes observações podem ser indicadas:

As taxas de juros aplicadas aos empréstimos, tanto para consumidor como para empresas, foram e continuam excessivamente altas. Por outro lado, apesar de as taxas serem e continuarem altas, estas vêm mostrando

Tabela 2: Taxa de juros nominal no Brasil e na área do euro (média por ano em agosto/2004)

\begin{tabular}{|c|c|c|}
\hline & Brasil & Euro Área \\
\hline \multicolumn{3}{|l|}{ Taxa de captação } \\
\hline Pessoa física & 15,18 & 1,91 \\
\hline Pessoa jurídica & 15,18 & 1,98 \\
\hline \multicolumn{3}{|l|}{ Taxa de aplicação } \\
\hline Cheque especial & 140,62 & 9,62 \\
\hline Pessoa física & 63,1 & 7,67 \\
\hline Pessoa jurídica & 40,47 & 4,06 \\
\hline \multicolumn{3}{|c|}{$\begin{array}{l}\text { Fonte: Para o Brasil, Banco Central. Disponível em: www.bcb.gov.br/?Serietemp. Para a zona do euro, Banco Central Europeu } \\
\text { (European Central Bank). Disponível em: www.ecb.int/press/pr/stats/mfi/html/index.em.html. Acesso em: } 14 \text { out. } 2004 .\end{array}$} \\
\hline \multicolumn{3}{|c|}{$\begin{array}{l}\text { Nota: A taxa de captação na área do euro é definida como taxa de juros até um ano do vencimento, paga sobre depósitos da } \\
\text { pessoa física e depósitos do setor não financeiro. A taxa de aplicação é a taxa de juros paga sobre empréstimos para consumo } \\
\text { das famílias e sobre empréstimos para empresas não financeiras. Para a taxa de captação no Brasil foi utilizada a taxa média de } \\
\text { certificados de depósitos bancários (CDBs) emitidos pelo sistema bancário. }\end{array}$} \\
\hline
\end{tabular}


uma tendência declinante, interrompida nas situações em que a economia brasileira passou a sofrer as influências de choques externos, e, conseqüentemente, o Banco Central passou a moldar sua política de juros de acordo com os acontecimentos no cenário externo. Assim, as taxas de juros aumentaram em janeiro de 1995, como resposta à crise do México; novembro de 1997, como resposta à crise da Ásia; outubro de 1998, como resposta à crise da Rússia; fevereiro de 1999, como resposta à crise cambial brasileira; e abril de 2001, como resposta à crise da Argentina, aumentando novamente no final de 2002 como resultado da incerteza política que acompanhou as eleições presidenciais do Brasil.

Gráfico 2: Brasil, evolução das taxas reais de juros

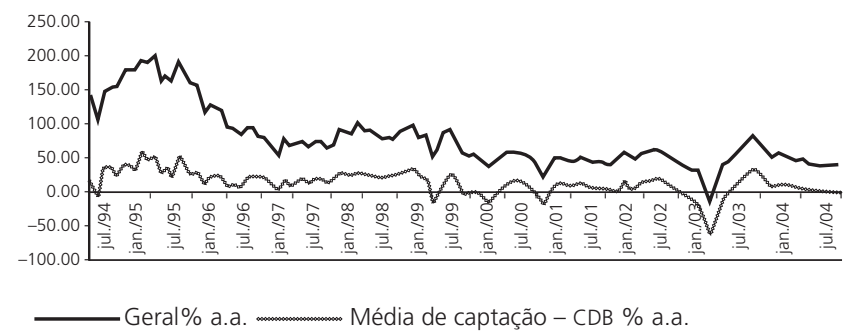

Fonte dos dados brutos: Banco Central do Brasil. Disponível em: www.bcb.gov.br/?Serietemp. Dados mensais anualizados. Elaboração do autor. Acesso em: 27 set. 2004.

Nota: Os dados foram deflacionados pelo IGP-M da FGV. ${ }^{1}$

Gráfico 3: Brasil, evolução das taxas reais de juros

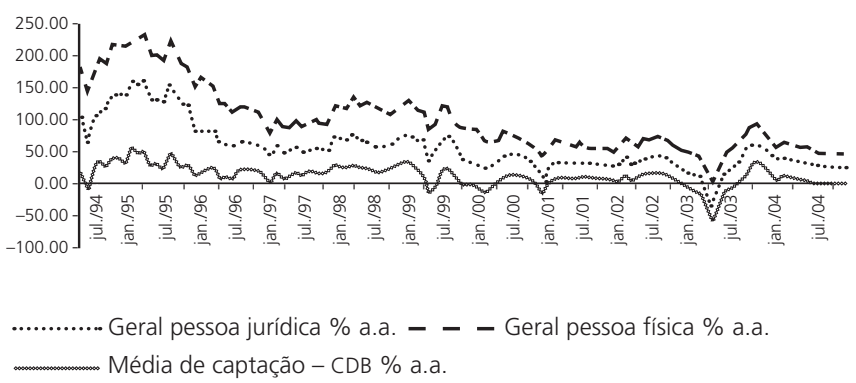

Fonte dos dados brutos: Banco Central do Brasil. Disponível em: www.bcb.gov.br/?Serietemp.

Dados mensais anualizados. Elaboração do autor. Acesso em: 27 set. 2004.

Nota: Os dados foram deflacionados pelo IGP-M da FGV. 
A tabela 3 mostra as taxas de juros reais cobradas nos empréstimos aos consumidores (pessoa física), no Brasil, entre 1994 e agosto de 2004. Nesse período, o custo médio geral de crédito pessoal ficou entre 53,3 e 174,5\%, com média de quase 78,5\%; entre 126,6 e 254,4\%, com média de 166,9\% em caso de cheque especial; e entre 57,7 e 198,7\%, com média de 102,7\% em caso de categoria de crédito direto ao consumidor. Já para o setor empresarial (tabela 4), as taxas de juros cobradas sempre foram inferiores àquelas praticadas ao consumidor e tiveram seus níveis mínimos em 2002 e máximos em 1995. A taxa geral ficou entre 35,3 e 174,1\%, com média de 78,5\%; a taxa cobrada no desconto de duplicata ficou entre 22,9 e 145,3\%, com média de 63,8\% e para capital de giro, a taxa ficou entre 10,4 e 143,1\%, com média de $54,2 \%$.

Verificando-se o comportamento e a magnitude do spread bancário, que é definido como a diferença entre as taxas pagas na captação de recursos no mercado (taxas de remuneração do depositante que são geralmente mais baixas do que a taxa de CDB utilizado neste estudo como proxy) e as taxas cobradas nos empréstimos aos clientes (custo ao tomador final), os dados (tabelas 3 e 4) mostram que, de julho de 1994 a agosto de 2004, o sistema

Tabela 3: Brasil - evolução da média anual das taxas de juros reais anualizadas e spread bancário \%, pessoa física

\begin{tabular}{|c|c|c|c|c|c|c|c|c|c|c|}
\hline & \multicolumn{3}{|c|}{ Taxa de aplicação } & \multirow[t]{2}{*}{$\begin{array}{c}\text { Taxa de } \\
\text { captação }\end{array}$} & \multicolumn{3}{|c|}{ Spread } & \multicolumn{3}{|c|}{$\begin{array}{c}\text { Spread/taxa } \\
\text { de captação (\%) }\end{array}$} \\
\hline & Geral & $\begin{array}{l}\text { Cheque } \\
\text { especial }\end{array}$ & $\begin{array}{l}\text { Crédito } \\
\text { pessoal } \\
(C D C)\end{array}$ & & Geral & $\begin{array}{l}\text { Cheque } \\
\text { especial }\end{array}$ & $\begin{array}{l}\text { Crédito } \\
\text { pessoal }\end{array}$ & Geral & $\begin{array}{l}\text { Cheque } \\
\text { especial }\end{array}$ & $\begin{array}{l}\text { Cheque } \\
\text { pessoal }\end{array}$ \\
\hline 1994 & 146,1 & 233,0 & 177,4 & 61,4 & 84,7 & 171,6 & 116,0 & 138,1 & 279,6 & 188,9 \\
\hline 1995 & 174,5 & 254,4 & 198,7 & 52,5 & 122,0 & 201,9 & 146,2 & 232,6 & 384,9 & 278,6 \\
\hline 1996 & 96,9 & 176,5 & 120,4 & 26,0 & 70,8 & 150,5 & 94,3 & 271,9 & 577,7 & 362,2 \\
\hline 1997 & 71,5 & 150,0 & 101,7 & 23,6 & 47,9 & 126,4 & 78,1 & 203,2 & 536,4 & 331,5 \\
\hline 1998 & 86,4 & 175,6 & 118,1 & 25,6 & 60,7 & 149,9 & 92,4 & 236,7 & 584,5 & 360,3 \\
\hline 1999 & 60,9 & 148,1 & 85,3 & 23,2 & 37,7 & 124,9 & 62,1 & 162,7 & 538,8 & 267,9 \\
\hline 2000 & 46,9 & 141,2 & 60,6 & 17,0 & 29,9 & 124,1 & 43,5 & 175,3 & 728,4 & 255,3 \\
\hline 2001 & 47,1 & 142,8 & 67,4 & 17,3 & 29,8 & 125,5 & 50,1 & 172,8 & 726,9 & 290,4 \\
\hline 2002 & 35,3 & 132,0 & 57,7 & 18,8 & 16,5 & 113,2 & 38,9 & 87,6 & 602,0 & 206,9 \\
\hline 2003 & 57,6 & 155,9 & 82,0 & 21,6 & 36,0 & 134,3 & 60,3 & 166,3 & 620,2 & 278,7 \\
\hline 2004 & 40,7 & 126,6 & 60,1 & 15,1 & 25,6 & 111,6 & 45,0 & 169,7 & 739,3 & 298,1 \\
\hline Média & 78,5 & 166,9 & 102,7 & 27,5 & 51,1 & 139,4 & 75,2 & 183,4 & 574,4 & 283,5 \\
\hline
\end{tabular}


Tabela 4: Brasil - evolução das Taxas de juros reais e spread bancário \%, pessoa jurídica

\begin{tabular}{|c|c|c|c|c|c|c|c|c|c|c|}
\hline & \multicolumn{3}{|c|}{ Taxa de aplicação } & \multicolumn{3}{|c|}{ Taxa de captação spread } & \multicolumn{4}{|c|}{ Spread/taxa de captação (\%) } \\
\hline & Geral & $\begin{array}{l}\text { Desconto } \\
\text { duplicata }\end{array}$ & $\begin{array}{l}\text { Capital } \\
\text { de giro }\end{array}$ & & Geral & $\begin{array}{l}\text { Desconto } \\
\text { duplicata }\end{array}$ & $\begin{array}{l}\text { Capital } \\
\text { de giro }\end{array}$ & Geral & $\begin{array}{l}\text { Desconto } \\
\text { duplicata }\end{array}$ & $\begin{array}{l}\text { Capital } \\
\text { de giro }\end{array}$ \\
\hline 1994 & 146,1 & 111,5 & 109,7 & 61,4 & 84,7 & 50,2 & 48,3 & 138,1 & 81,7 & 78,6 \\
\hline 1995 & 174,5 & 145,3 & 143,1 & 52,5 & 122,0 & 92,8 & 90,6 & 232,6 & 176,9 & 172,7 \\
\hline 1996 & 96,9 & 79,4 & 65,1 & 26,0 & 70,8 & 53,3 & 39,1 & 271,9 & 204,8 & 150,1 \\
\hline 1997 & 71,5 & 65,9 & 54,1 & 23,6 & 47,9 & 42,4 & 30,5 & 203,2 & 179,7 & 129,5 \\
\hline 1998 & 86,4 & 77,2 & 64,2 & 25,6 & 60,7 & 51,5 & 38,5 & 236,7 & 200,9 & 150,1 \\
\hline 1999 & 60,9 & 55,1 & 41,8 & 23,2 & 37,7 & 31,9 & 18,6 & 162,7 & 137,5 & 80,2 \\
\hline 2000 & 46,9 & 38,1 & 28,1 & 17,0 & 29,9 & 21,1 & 11,1 & 175,3 & 123,7 & 64,9 \\
\hline 2001 & 47,1 & 37,0 & 25,2 & 17,3 & 29,8 & 19,7 & 7,9 & 172,8 & 114,4 & 45,9 \\
\hline 2002 & 35,3 & 22,9 & 10,4 & 18,8 & 16,5 & 4,1 & $-8,4$ & 87,6 & 21,7 & $-44,7$ \\
\hline 2003 & 57,6 & 43,3 & 33,1 & 21,6 & 36,0 & 21,7 & 11,4 & 166,3 & 100,1 & 52,7 \\
\hline 2004 & 40,7 & 26,7 & 21,3 & 15,1 & 25,6 & 11,6 & 6,2 & 169,7 & 77,0 & 40,9 \\
\hline Média & 78,53 & 63,86 & 54,2 & 27,47 & 51,07 & 36,39 & 26,70 & 183,36 & 128,94 & 83,72 \\
\hline
\end{tabular}

Fonte: Banco Central do Brasil. DEPEC. Disponível em: www.bcb.gov.br/?serietemp. Média anual de dados mensais anualizados. Elaboração do autor. Acesso em: 27 set. 2004.

Nota: Os dados foram deflacionados pelo IGP-M da FGV.

Tabela 5: Spread bancário - diversos países (\%)

\begin{tabular}{|c|c|c|c|c|c|c|}
\hline Países desenvolvidos & 1995 & 1996 & 1997 & 1998 & 1999 & 2000 \\
\hline EUA & 2,91 & 2,88 & 2,82 & 2,88 & 2,66 & 2,77 \\
\hline Canadá & 1,50 & 1,73 & 1,37 & 1,57 & 1,53 & 1,57 \\
\hline Japão & 2,50 & 2,36 & 2,15 & 2,05 & 2,04 & 2,00 \\
\hline Reino Unido & 2,58 & 2,91 & 2,95 & 2,73 & - & - \\
\hline França & 3,62 & 3,1 & 2,84 & 3,34 & 3,67 & 4,07 \\
\hline \multicolumn{7}{|l|}{ América Latina } \\
\hline Argentina & 5,95 & 3,15 & 2,27 & 3,08 & 2,99 & 2,75 \\
\hline BRASIL(1) & 130,45 & 67,79 & 54,62 & 60,71 & 57,50 & 38,72 \\
\hline$\underline{\text { BRASIL }}$ & - & - & 53,84 & 58,36 & 54,42 & 38,57 \\
\hline Chile & 4,43 & 3,91 & 3,65 & 5,26 & 4,07 & 5,64 \\
\hline Colômbia & 10,38 & 10,84 & 10,09 & 9,66 & 9,08 & 14,21 \\
\hline México & 20,47 & 12,19 & 9,89 & 14,95 & 16,26 & 11,96 \\
\hline Uruguai & 60,86 & 63,39 & 51,94 & 42,84 & 39,03 & 36,94 \\
\hline \multicolumn{7}{|l|}{ Ásia } \\
\hline Coréia & 0,20 & 1,30 & 1,10 & 2,00 & 1,50 & 0,60 \\
\hline Malásia & 1,70 & 1,80 & 1,75 & 2,00 & 3,17 & 3,41 \\
\hline Cingapura & 2,87 & 2,85 & 2,85 & 2,10 & 4,12 & 4,12 \\
\hline Tailândia & 1,67 & 3,07 & 3,13 & 2,84 & 4,25 & 4,54 \\
\hline
\end{tabular}

Fonte: IMF. Internacional Financial Statistics, dez. 2001.

Note: Dados nominais. (1) cálculo do autor segundo os dados do Banco Central do Brasil. 
financeiro brasileiro vem praticando spread recorde, com média real anual de $51 \%$, sendo $36,4 \%$ e $26,7 \%$ para as empresas nas categorias de desconto de duplicata e capital de giro, e 75,2\% e 139,4\% para pessoas físicas nas categorias de crédito direto ao consumidor e cheque especial respectivamente (tabelas 3 e 4).

Por outro lado, verificando-se a relação spread/taxa de captação, os dados mostram que a taxa média de lucro real bruto sobre empréstimos ao setor privado foi de $183,4 \%$, sendo 128,9 e $83,7 \%$ nas categorias de empréstimo para o setor empresarial, e 574,4 e 283,5\% nas categorias do consumidor.

Em relação aos outros países, a tabela 5 mostra que o spread bancário no Brasil é um dos mais altos do mundo: no período de 1997 a 2000, foi, na média, 3,6 vezes o spread de países da América Latina; 20,2 vezes o de países desenvolvidos, e 18,6 vezes o de países da Ásia. Esses dados evidenciam a gravidade do problema que o setor privado enfrenta em financiar seus gastos, tanto sobre consumo como sobre investimento.

\section{POR QUE AS TAXAS DE JUROS SÃO TÃO ALTAS?}

No Brasil, a atual circunstância desafia a lógica da economia keynesiana, ou o que é conhecido nos livros-textos de macroeconomia como modelo macroeconômico de curto prazo (Hall, 2003, p. 253-292), que enfatiza o papel dos gastos como determinante principal da renda. Em face das taxas de crescimento insignificantes nos últimos anos, altas taxas de desemprego, falta de investimento e diminuição do consumo, Keynes (1936) defende que, em tal situação, o governo deve aumentar os gastos públicos. Mas a política praticada é a diminuição dos gastos públicos e o aumento dos superávits no orçamento do governo. Defende que o consumo deve ser incentivado através das políticas de redução de impostos e tributos, mas a política praticada é a de diminuir o consumo, por meio de aumento de tributos (CPMF). Defende que a taxa de juros deve cair, mas a taxa está aumentando e encontra-se entre as mais altas do mundo.

Quatro são os fatores chave que podem fornecer explicação para a alta da taxa de juros: estabilizar preços via contenção da demanda interna; garantir o financiamento do déficit em transações correntes; evitar ataques especulativos contra o câmbio; e altos spreads cobrados pelos bancos aos empréstimos para o setor privado. 


\subsection{Estabilizar preços via contenção da demanda interna}

Considerando a história da inflação alta e crônica do país, o governo brasileiro, em junho de 1994, colocou em prática um programa de estabilização com o objetivo de reduzir e estabilizar a inflação. As contribuições de Pigou, (1941) e Patinkin (1965) deixaram claro que a queda dos preços aumenta a riqueza das famílias e, conseqüentemente, leva à expansão da demanda privada. Os dois economistas observaram que os saldos monetários reais são parte da riqueza dos indivíduos. Assim, quando os preços caem, os saldos monetários reais aumentam, as famílias se sentem mais ricas e, conseqüentemente, aumentam o consumo.

Segundo dados publicados pelo Banco Central, logo após a implementação do Plano Real, o consumo aumentou em todas as categorias de produtos, principalmente nos bens de consumo duráveis. $\mathrm{O}$ aumento de consumo decorreu da grande expansão do crédito pessoal, eliminação da ilusão monetária e acréscimo do salário. Um estudo feito por Mattoso e Baltar (1997, p. 294-314) indicou que o aumento do salário mínimo, logo no começo do Plano Real, combinado com o rápido declínio da inflação e o aquecimento do nível de atividades econômicas, permitiu o crescimento no rendimento de $30 \%$ entre 1994 e $1996 .^{2}$

O governo, preocupado com o aumento do consumo, e para evitar a explosão da demanda agregada que pudesse desestabilizar a economia com o retorno da inflação, aumentou a taxa de juros, através de implementação de uma política monetária restritiva.

\subsection{Necessidade de financiamento do setor externo}

\subsubsection{Mobilidade de capital, conta-corrente e taxa de juros}

A integração financeira internacional e a mobilidade de capital, a partir do começo dos anos 1980, resultaram em três conseqüências principais em relação à condução da política macroeconômica. Segundo publicação do Bank for International Settlements (1986, p. 249), os países que sofrem problemas no balanço de pagamentos enfrentam menos dificuldades em financiar seus déficits na conta-corrente. Tal fato significa que os governos podem escolher atrasar a implementação das políticas necessárias de ajuste das contas externas por períodos além do possível na ausência de mobilidade de capital. 
Por outro lado, e como sugere Richard Libsey (1988, p. 1-11), no regime de câmbio flutuante, é muito mais fácil sustentar o ponto de vista que implica a conta de capital, esta responsável pelos movimentos de taxa de câmbio. Assim, a diminuição na poupança interna pode ser compensada por influxos de capital externo no aspecto financeiro da balança de pagamentos e por aumento do déficit, na conta-corrente, induzido por apreciação cambial.

A terceira conseqüência é que a transmissão dos efeitos da política monetária sobre a economia desloca-se da taxa de juros para a taxa de câmbio. Nesse aspecto, e no contexto do regime de taxa de câmbio flutuante, a política monetária se torna uma política cambial, dado que qualquer aumento nas taxas de juros se transforma para apreciação cambial (Mundell, 1963, p. 475-485).

No período de julho de 1994 até a crise cambial em janeiro de 1999, o Brasil adotou uma política cambial conhecida como "banda cambial", na qual a taxa de câmbio foi o principal instrumento responsável para controle da inflação. Dado o déficit crescente na conta-corrente do balanço de pagamentos, o governo foi obrigado a aumentar as taxas de juros com o objetivo de, primeiro, incentivar a entrada de capital externo, e, em segundo lugar, prevenir as saídas desses capitais.

Essa política teve seus limites em janeiro de 1999, quando o real foi desvalorizado. O governo abandonou o regime de banda cambial e colocou em prática um sistema de metas de inflação. O papel da taxa de juros e da taxa de câmbio foi invertido. Assim, o papel da taxa de juros era o de controlar a inflação, enquanto o da taxa de câmbio era responsável por equilibrar o balanço de pagamentos.

\subsubsection{Setor externo brasileiro}

Com o objetivo de garantir a estabilidade de preços, o governo brasileiro estimulou as importações como meio de aumentar a oferta agregada na economia. Os instrumentos principais, nesse contexto, foram a abertura econômica, acompanhada pela valorização cambial e redução das tarifas alfandegárias.

Apesar de essas medidas terem sido viáveis para alcançar o objetivo proposto, o resultado foi um déficit enorme na conta-corrente, que necessitou ser financiado pela entrada do capital estrangeiro. 
O quadro geral dos principais indicadores do setor externo, no Brasil, está resumido na tabela 6 . As seguintes constatações podem ser feitas: primeiro, desde o Plano Real, em 1994, o déficit em transações correntes que engloba a balança comercial mais a balança de serviços passou de US\$1,4 bilhão em 1994 para US\$33,4 bilhões em 1998, e depois mostrou uma tendência declinante até alcançar um superávit de US\$ 4 bilhões em 2003, e aproximadamente US\$11,6 bilhões em 2004. O déficit acumulado no período foi aproximadamente de US\$ 168 bilhões. Segundo, a balança comercial, que até 1994 vinha apresentando saldos positivos, começou, a partir de 1995, a apresentar saldos negativos, impulsionados pelo aumento das importações em taxas superiores ao aumento das exportações. Essa tendência começou a ser revertida em 2001, após a desvalorização cambial, ocasionada pelo aumento das exportações e queda das importações. Terceiro, o que é evidente é que a principal força motriz responsável pelo déficit na contacorrente são as rendas do capital estrangeiro, na forma de remessa de lucro das empresas estrangeiras no país, e da taxa de juros paga sobre a dívida externa brasileira, bem como da taxa de juros paga pelo capital especulativo (portfolio), o qual entra no país aproveitando as taxas de juros altas. Nesse sentido, é importante salientar que o total de rendas pagas aos estrangeiros no período de 1991 a 2003 acumulou cerca de US\$ 217 bilhões, sendo US\$ 163 bilhões ou 75\% do total remessas de juros, responsáveis por quase $90 \%$ do déficit da conta-corrente. Quarto, a fragilidade do setor externo fica evidente no fato de que mais de $100 \%$ do déficit na conta-corrente é o resultado dos juros e lucros remitidos ao exterior.

Diante desse quadro do setor externo e na ausência de existência de reservas internacionais de volume expressivo, o governo tem quatro meios de financiar suas obrigações externas: alcançar saldos positivos e enormes na balança comercial; incentivar a entrada de capital externo direto, na forma de instalar novas empresas ou adquirir empresas estatais que foram privatizadas; incentivar a entrada do capital estrangeiro na forma de portfolio, utilizando taxas de juros altas; e, finalmente, conseguir empréstimos do FMI.

Verificando os números nas colunas 9, 10 e 11 da tabela 6, observa-se que os fluxos do capital estrangeiro foram mais do que suficientes para financiar o déficit na conta-corrente, sendo cerca de $47 \%$ na forma de capital de portfolio incentivado pelas altas taxas de juros. Até 1996, a entrada desse capital 


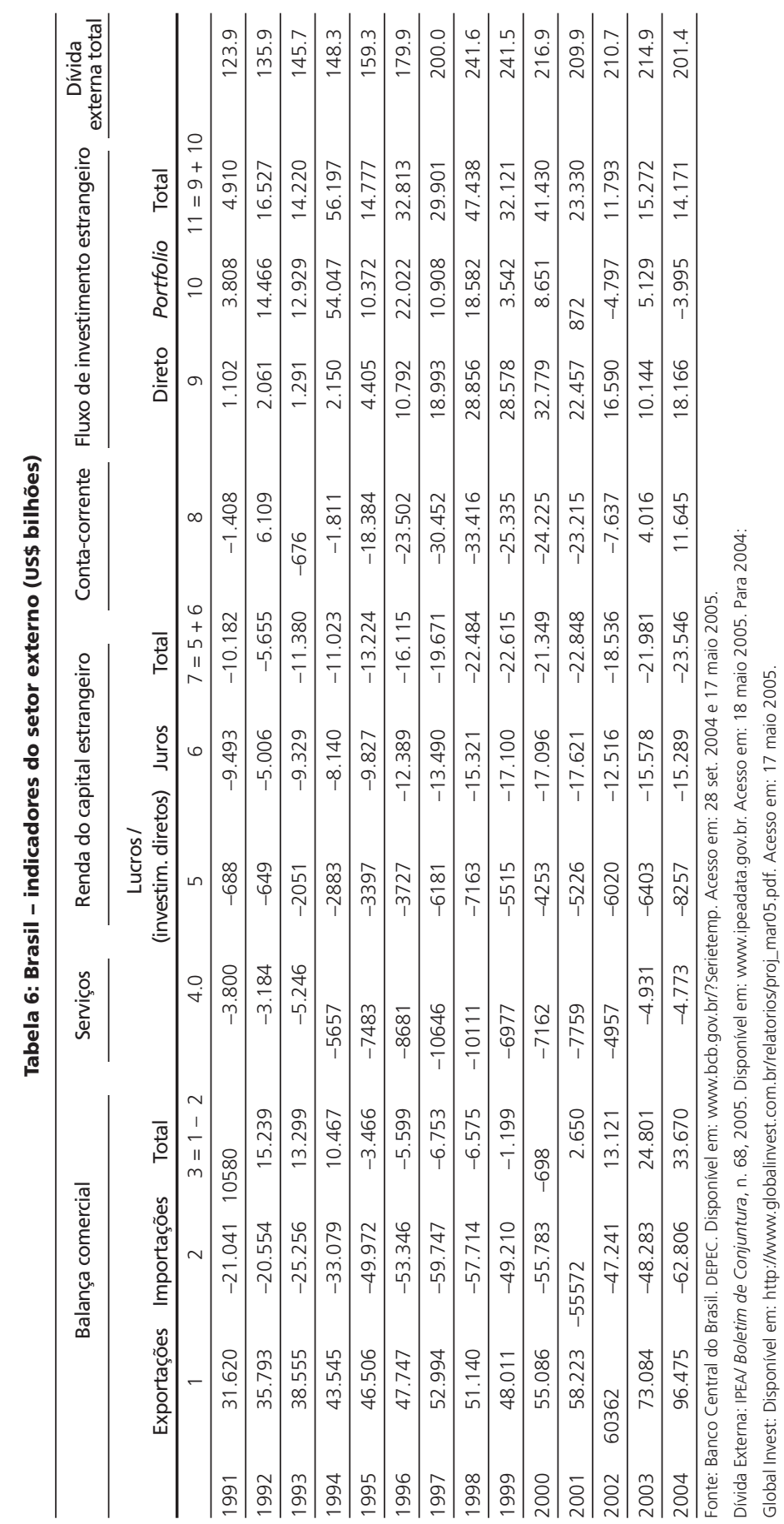


sempre foi superior ao investimento direto, e em certos anos (1994) foi 15 vezes superior ao primeiro. A partir de 1997, e como reflexo de crises financeiras internacionais, a entrada desse capital teve uma tendência declinante e chegou a um patamar negativo em 2002. Nesse sentido, Belluzzo (2004, p. 2) afirmou:

É preciso recordar que, desde 1995, depois da crise mexicana, a taxa básica de juros se manteve num patamar muito elevado para sustentar o financiamento do déficit em transações correntes e acumulação de reservas.

\subsection{Evitar ataques contra a moeda nacional: a relação entre taxa de juros e taxa de câmbio}

A condição da paridade de taxa de juros (Baumann, Canuto e Gonçalves, 2004, p. 272-273 e p. 324-326) implica que, quando uma economia liberaliza a sua conta de capital, perde o grau de liberdade para fixar a sua taxa de juros. Isso é relacionado aos fluxos de capitais. Em regime de câmbio fixo, a taxa de juros baixa causará saídas de capital, o que causa contração monetária e, conseqüentemente, o aumento da taxa de juros. Sob regime de câmbio flexível, a diminuição da taxa de juros ocasionará fuga de capital, o que leva à depreciação da taxa de câmbio.

A taxa de câmbio, como âncora nominal, foi recomendada para países que sofriam com a alta inflação e com um elevado grau de dívida externa por duas razões principais: os estudos mostram que há uma estreita relação entre a estabilidade cambial e uma baixa taxa de inflação. Isso resulta de um efeito disciplinatório (Ghosh et al., 1997, p. 2), no sentido de que as autoridades políticas temem o alto custo político de abandonar a estabilidade do câmbio, assim induzindo políticas monetárias restritivas e disciplinatórias.

Existe também o efeito credibilidade (Caramazza e Jahangir, 1998, p. 4), segundo o qual uma maior confiança na moeda doméstica leva a uma maior disponibilidade de retenção da moeda nacional, em troca da aquisição de bens ou moedas estrangeiras. Além disso, para países com um elevado endividamento externo, o FMI recomenda o uso da taxa de câmbio como âncora nominal. Isso é visto e considerado essencial, porque a depreciação da taxa de câmbio incrementa a dívida em moeda estrangeira e pode levar a falências no setor privado, bem como se torna difícil aos países cumprirem seus 
compromissos externos; por isso, há a insistência de que a taxa de juros se mantenha alta, mesmo quando isso supõe colocar poderosas forças deflacionárias em funcionamento (Wyplosz, 1998, p. 15).

\subsection{Estrutura de mercado bancário}

Resultados de diferentes estudos do Banco Central sobre a composição de spread bancário $(1999,2000,2001,2002,2003)$ mostram que seu principal componente é a taxa de lucro (tabela 7).

Os dados mostram que, no período de 1999 a 2003, o spread bancário, na média, é composto por $16 \%$ de taxa de risco, $18 \%$ de despesas administrativas, $29 \%$ de impostos e $38 \%$ de lucro dos bancos. Uma taxa de lucro de quase $40 \%$ é alta e não compatível com a realidade de uma economia que não está crescendo.

Alguns autores (Cintra e Etlin, 2003, p. 22-23) levantam a hipótese de que uma taxa de lucro de $40 \%$ por ano é o resultado do grau de concentração bancária no Brasil:

É fundamental, na análise dos juros, considerar o setor bancário como um oligopólio, onde poucos bancos detêm poder de mercado para fixar as taxas dos empréstimos (...) o setor bancário tem sido concentrado muito nos últimos anos. Entre 1994 e 2001 foram 181 fusões e aquisições, com o número de bancos no período caindo de 246 para 180 . Os cinco maiores bancos concentram 49,75 dos ativos totais, 55,3\% dos empréstimos e 57,9\% dos depósitos bancários. No mesmo período a participação dos dez maiores bancos no total dos ativos saltou de 65,15 para 73,65 (...) O poder dos bancos fica claro quando se vê que só com a receita das tarifas, cobrem mais de $100 \%$ da folha de salários do setor.

Tabela 7: Composição do spread - agosto de cada ano

\begin{tabular}{lcccccc}
\hline & 1999 & 2000 & 2001 & 2002 & 2003 & Média \\
\hline Despesas de Inadimplência & $11 \%$ & $14 \%$ & $17 \%$ & $17 \%$ & $19 \%$ & $16 \%$ \\
\hline Despesas Administrativas & $20 \%$ & $18 \%$ & $19 \%$ & $14 \%$ & $17 \%$ & $18 \%$ \\
\hline Impostos Indiretos + FGC & $12 \%$ & $9 \%$ & $8 \%$ & $8 \%$ & $8 \%$ & $9 \%$ \\
\hline Impostos Diretos & $21 \%$ & $20 \%$ & $19 \%$ & $21 \%$ & $19 \%$ & $20 \%$ \\
\hline Lucro Líquido dos Bancos & $36 \%$ & $39 \%$ & $37 \%$ & $40 \%$ & $37 \%$ & $38 \%$ \\
\hline Total & $100 \%$ & $100 \%$ & $100 \%$ & $100 \%$ & $100 \%$ & \\
\hline
\end{tabular}

Fonte dos dados brutos: Banco Central do Brasil: Economia bancária e crédito. Avaliação de 4 anos do projeto Juros e Spread Bancário, p. 18. Disponível em: www.bcb.gov.br/ftp_economia_bancaria_credito.pdf. Acesso em: 24 jul. 2004. 
Estudos empíricos feitos por Tonooka e Koyama (2003) e Afanasieff, Lhacer e Nakane (2002) sugerem que não existe muito fundamento na idéia de que os elevados spreads bancários observados no país sejam decorrência da alta concentração no setor bancário do país. No estudo de Tonooka e Koyama (p. 19) foi concluído que

os bancos não atuariam como um cartel na fixação das taxas de juros sobre empréstimos", portanto, a recomendação principal deles é de que, "a intervenção governamental no sentido de diminuir o grau de concentração dos mercados seria inócua para diminuir as taxas de juros.

Nakane (2003, p. 65) sugere que podem existir outras formas que explicam o comportamento anticompetitivo no setor. Ele cita que

práticas adotadas pelo banco para fidelizar o cliente podem ser utilizadas para extrair rendas informacionais do mesmo. Medidas de fidelização aumentam os custos de transferência (switching costs), criando um efeito lock in que prende o cliente ao banco.

A teoria econômica nos informa que as taxas baixas de captação desincentivam a poupança, enquanto as taxas altas, os investimentos. Qual a lógica, então, que força os poupadores a aceitar taxas baixas e os investidores taxas altas? Se a poupança é função da taxa de juros, segundo os clássicos, e da renda, segundo Keynes, como essa equação é forçada sobre o mercado de crédito? Se o mercado bancário funciona como mercado competitivo, as taxas de captação e de aplicação devem ficar em um patamar próximo, e sem muita discrepância. Num mercado concorrente, não existem lucros "extraordinários" a longo prazo. A persistência das altas taxas de lucro no setor é uma das características dos mercados oligopolistas e monopolistas. Recentemente, o economista da FGV Marcos Cintra (2005, p. 12), citando estudos empíricos e afirmações dos economistas do Fundo Monetário Internacional (FMI), que evidenciam a atuação oligopolista dos bancos no Brasil, chamou a atenção para a falta de concorrência e poder dos bancos na formação da taxa de juros praticada no mercado nacional. De fato, dados publicados pela Conjuntura Econômica (p. 42-43, nov., 2004) sobre os maiores 100 bancos na economia brasileira mostram alto índice de concentração bancária, onde os maiores 10 bancos possuem 70\% dos ativos, $66 \%$ das operações de crédito e quase $66 \%$ das receitas de intermediação financeira. 


\section{IMPLICAÇÕES PARA A ECONOMIA BRASILEIRA, SE OS JUROS CONTINUAREM ALTOS}

\subsection{Setor produtivo}

O papel da taxa de juros na determinação de nível de investimentos e, por conseqüência, de crescimento econômico foi analisado e discutido na teoria econômica, tanto da escola clássica como da escola keynesiana. Os clássicos enfatizaram que o investimento é determinado, exclusivamente, pela taxa de juros (Rima, 1990, p. 473).

Keynes (1983, cap. 11), por sua vez, sugeriu dois fatores como determinantes fundamentais dos gastos com investimento: a taxa de juros e as expectativas das firmas de lucratividade futura dos projetos de investimentos. Keynes chamou o retorno esperado que um empresário pode obter de um novo investimento de Eficiência Marginal do Capital (EMC). Assim, quanto maior a lucratividade futura, maior o nível do investimento. Conseqüentemente, a EMC depende do custo do capital, que é a taxa de juros. Sendo assim, quando a taxa de juros sobe, certos projetos tornam-se inviabilizados.

A tabela 8 nos mostra dados sobre a taxa de variação do PIB real e PIB real per capita, no Brasil, no período de 1990 a 2004. Os dados mostram que, embora as taxas de crescimento sejam positivas, elas vinham caindo até 1999, subiram para 4,3\% em 2000, depois seguiram uma tendência de declínio até 2004, quando a taxa de crescimento alcançou 5,2\%, maior taxa alcançada nos últimos nove anos. O PIB acumulou crescimento de 31,4\%, com média anual de $2,1 \%$ no período. $\mathrm{O}$ quadro se torna muito mais sério verificando os dados sobre crescimento do PIB per capita que acumulou crescimento de $8,9 \%$, com média anual de $0,6 \%$. O nível de investimento em relação ao PIB manteve sua tendência de estagnação e mostrou tendência declinante a partir de 1996, quando alcançou níveis inferiores aos de 1990. O efeito perverso das altas taxas de juros sobre investimento no Brasil foi verificado em uma pesquisa de Fiesp junto à FGV, na qual foi mostrado que quase 50\% dos investimentos dos cerca de 400 empresários entrevistados, de todos os portes e diferentes setores da indústria, são próprios (Messer, 2003, p. 98).

Como resultado da estagnação da produção e do investimento, a taxa de desemprego, que foi no patamar de 5\% em 1994, vem aumentando na for- 
Tabela 8: Indicadores macroeconômicos (\%)

\begin{tabular}{|c|c|c|c|c|c|c|c|c|c|c|c|c|c|c|c|}
\hline & 1990 & 1991 & 1992 & 1993 & 1994 & 1995 & 1996 & 1997 & 1998 & 1999 & 2000 & 2001 & 2002 & 2003 & 2004 \\
\hline PiB real & $-4,3$ & 1 & $-0,5$ & 4,9 & 5,9 & 4,2 & 2,7 & 3,3 & 0,1 & 0,8 & 4,4 & 1,3 & 1,9 & 0,5 & 5,2 \\
\hline $\begin{array}{l}\text { PiB } \\
\text { per capita }\end{array}$ & $-5,8$ & $-0,5$ & -2 & 3,4 & 4,4 & 2,7 & 1,2 & 1,8 & $-1,4$ & $-0,7$ & 2,9 & $-0,2$ & 0,4 & $-1,0$ & 3,7 \\
\hline $\begin{array}{l}\text { FBCF } \\
\text { Preços correntes }\end{array}$ & 20,7 & 18,1 & 18,4 & 19,3 & 20,8 & 20,5 & 19,3 & 19,9 & 19,7 & 18,9 & 19,3 & 19,5 & 18,3 & 17,8 & \\
\hline $\begin{array}{l}\text { Desemprego } \\
\text { aberto (Brasil) }\end{array}$ & 4,3 & 4,8 & 5,7 & 5,3 & 5,1 & 4,6 & 5,4 & 5,7 & 7,6 & 7,6 & 7,1 & 6,2 & 11,7 & 12,3 & 11,5 \\
\hline
\end{tabular}

Fonte: IPEA: Boletim de Conjuntura, n. 68, 2005. Disponível em: www.ipeadata.gov.br. Acesso em: 18 maio 2005.

Nota: PIB per capita calculado estimando uma taxa de crescimento da população da ordem de 1,5\% a.a.

ma crescente e alcançou 11,5\% em 2004. Esse é um preço muito alto a ser pago em nome da estabilidade econômica.

Para as economias emergentes, as mudanças das últimas décadas não invalidaram, senão confirmaram, a afirmação de Keynes no Treatise on Money, a respeito da determinação da taxa de juros em um ambiente internacional exposto à livre movimentação de capitais: A taxa de juro de um país é fixada por fatores externos e é improvável que o investimento doméstico alcance o nível de equilíbrio (ou seja, um valor compatível com o melhor aproveitamento dos fatores de produção disponíveis).

\subsection{Aumento da dívida pública}

Um dos maiores problemas enfrentados pela economia brasileira hoje é a dívida interna. A relação dívida interna/PIB, que era de 30\% em 1995, saltou para 52,4\% em abril de 2003. O patamar mais alto foi alcançado em 2002 $(57,4 \%)$, tendo sido o pico em setembro do mesmo ano, quando a relação dívida/PIB chegou a $63,5 \%$.

Como a dívida pública é resultado do déficit orçamentário, torna-se importante verificar os efeitos dos juros sobre o déficit orçamentário do governo brasileiro. Aqui, vale a pena fazer distinção entre dois tipos de déficit: o déficit primário, que representa todas as despesas do governo, exceto os pagamentos de juros, e o déficit operacional, que compreende todos os gastos do governo, incluindo os juros reais pagos sobre a dívida pública, menos a receita.

A distinção entre as duas componentes mostra o papel da dívida pública e dos juros no orçamento. O orçamento total estará em déficit a menos que 


\section{Gráfico 4: Evolução da dívida pública em relação ao PIB (\%)}

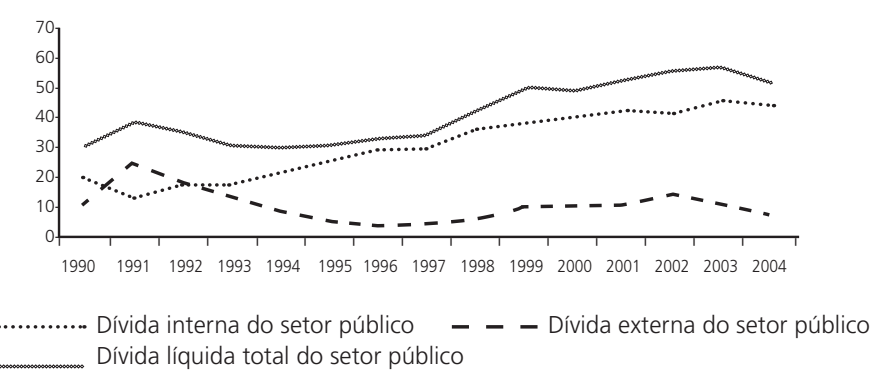

Fonte: IPEA: Boletim de Conjuntura, n. 68, 2005.

Disponível em: www.ipeadata.gov.br. Acesso em: 18 maio 2005.

os pagamentos de juros sobre a dívida sejam mais do que compensados por um superávit primário. Se houver um déficit primário no orçamento, então o déficit orçamentário total permanecerá crescendo; portanto, a dívida cresce e, conseqüentemente, os pagamentos de juros.

O papel da taxa de juros em aumentar a dívida pública fica evidente na seguinte situação: se a taxa média real de juros pago sobre a dívida pública é de $11 \%$ a.a., uma dívida equivalente a 52\% do PIB — sendo 57,5\% do montante dessa dívida indexados à taxa de juros Selic — paga, aproximadamente 3,3\% do PIB de juros reais. Mantidos todos os outros fatores constantes que levam ao aumento da dívida, isso implica que qualquer superávit primário inferior a esse número tende a aumentar a dívida de forma contínua.

Garcia (2002), em seu estudo sobre Public debt management, monetary policy and financial institutions, no período de 1995 a 2001, demonstrou que a taxa de juros foi o fator mais importante responsável pelo crescimento da dívida interna brasileira. Na sua totalidade, houve o aumento de $\mathrm{R} \$ 535.343 .380,00$ e a taxa de juros foi responsável sobre $61,04 \%$, seguido por acumulação da dívida dos estados da Federação, que contribui em 32,6\%.

\subsection{0 que deve ser feito para diminuir as taxas de juros}

\subsubsection{A diminuição da razão dívida pública/PIB}

É evidente que essa razão cai quando o PIB cresce mais rapidamente do que a dívida. Em vista de que a dívida pública é composta por títulos indexados à taxa de juros e câmbio e resulta de déficit orçamentário acumulado, Dorn- 
busch e Fischer (1993, p. 260) sugerem a seguinte fórmula para a evolução da razão dívida/PIB:

$\Delta b=b(r-y)-x$, onde:

$r=$ taxa de juros real

$x=$ superávit primário/PIB

$y=$ taxa de crescimento do PIB real

$b=$ razão dívida - PIB

Dado que parte da dívida está indexada ao câmbio, essa fórmula pode ser modificada para incluir a desvalorização (+)/valorização (-) cambial (c) como variável determinante. Assim, temos:

$\Delta b=b[(r+c)-y]-x$

Portanto, se:

$-b[(r+c)-y]-x$ maior que zero, $b$ está aumentado

$-b[(r+c)-y]-x$ menor que zero, $b$ está caindo

$-b[(r+c)-y]-x$ igual a zero, $b$ constante

Desse modo, a diminuição da razão dívida/PIB depende de quatro fatores: crescimento do PIB, superávit primário, diminuição de taxa de juros e valorização cambial.

Nesse contexto, para diminuir a razão dívida/PIB, e, assim, a necessidade de financiamento de déficit público, tendo por conseqüência a diminuição da taxa de juros, torna-se de grande urgência adotar as medidas necessárias para aumentar o PIB, aumentar o superávit primário e estabilizar a taxa de câmbio em nível compatível com as necessidades da política econômica.

\subsubsection{Política monetária expansionista}

Uma política monetária expansionista através de aumento da oferta monetária leva à diminuição temporária da taxa real de juros. Não existe argumento teórico ou evidência empírica que sustente que uma política monetária expansionista causa declínio permanente na taxa real de juros. Uma conseqüência adversa desse tipo de iniciativa consiste no aumento das expectativas inflacionárias, forçando aumento na taxa nominal de juros, causando efeitos adversos não esperados. 
Dadas as condições macroeconômicas em termos de taxas baixas de crescimento e taxa de desemprego elevada, e considerando que a inflação, atualmente, está associada a fatores da "oferta", e não da "demanda", particularmente com as variações dos preços administrados, uma política monetária expansionista e responsável pode ser recomendada sem medo de efeitos inflacionários. Até, se existe aumento de preço em certos setores da economia causado por excesso da demanda, isso não deve ser eliminado por aumento de taxa de juros. Nesse sentido, o papel da taxa de juros implica a anulação da principal função do mercado como alocador de recursos.

O aparente limite à expansão da atividade econômica, diferentemente dos países desenvolvidos, está na capacidade física instalada de alguns setores, particularmente o de bens intermediários... Mas, logo argumentará o economista do livro-texto: os preços aumentarão e teremos inflação. Isto é uma visão estática. E se ela prevalecer, jamais teremos crescimento. Para que o mercado funcione como um mecanismo de coordenação da atividade econômica, é preciso que os preços relativos aumentem, sinalizando para os empresários investirem em aumento da capacidade. Se, com elevação da taxa de juros e compressão, a demanda dos preços relativos for contida aqui, o mercado deixará de emitir esse sinal e a expansão econômica será impossível. Além disso, a elevação de preços em alguns setores não implica inflação, elevação generalizada de preços, e, muito menos, alta persistente de preços (...) Portanto, existe muito espaço para a redução da taxa de juros. Se isto acontecer, os aumentos de preços relativos dos setores com esgotamento da capacidade instalada levarão os empresários dos mesmos setores a investirem aumentando a sua capacidade produtiva (Nakano, 2004, p. 11).

\subsubsection{Política fiscal restritiva}

Restringindo os gastos do governo como forma de reduzir o déficit operacional, ou aumentando o superávit primário, pressiona-se a queda da taxa de juros. Por diminuir a demanda agregada, seja atual ou projetada, e por diminuir a incerteza sobre a monetização de futuros déficits orçamentários, essa iniciativa leva à diminuição da taxa de juros, em conseqüência da diminuição da taxa esperada da inflação. Essa política é utilizada atualmente no país com o objetivo de diminuir a razão dívida/PIB. Apesar de essa política poder alcançar o objetivo de diminuir a taxa de juros, seu preço é alto demais em termos de estagnação econômica e taxa alta de desemprego, além do corte nos gastos sociais, necessários para a sociedade. 


\subsubsection{Equacionamento do setor externo brasileiro}

O problema principal da economia brasileira reside no setor externo, ocasionado, principalmente, pela remessa de lucros e juros ao exterior.

A solução desse problema está sendo tratada de forma a alcançar superávit alto na balança comercial. Isso será saudável para a economia se os superávits forem convertidos em investimentos reais, seja dentro ou fora do país. Mas, se forem trocados em papel (US\$) para pagar os juros sobre a dívida externa, o resultado será o empobrecimento do país, por transferir recursos reais da economia aos outros, diminuindo a oferta agregada de bens, e assim a escassez do produto aumenta a inflação, e, por conseqüência, exige maior taxa de juros.

Um superávit comercial não deve ser sempre aplaudido, visto que poderá acarretar conseqüências negativas sobre a economia. Um superávit leva a que o governo opte entre aumentar o estoque da moeda em poder do público, conseqüentemente, aumentando a taxa de juros e expectativas futuras sobre a inflação, ou então esterilizar o superávit por emissão de títulos públicos e, assim, aumentar, mais ainda, a dívida pública interna e a taxa de juros. Dado que o objetivo principal do governo é diminuir e estabilizar a inflação, o país não pode acumular superávit comercial indefinitivamente, porque isso exige intervenção contínua para esterilizar esses superávits, e, portanto, aumentar de forma indefinida a dívida pública e, assim, a razão dívida/PIB.

Em 1994, o saldo da dívida interna líquida do setor público era de US\$ 65 bilhões. Hoje, o valor desse estoque, calculado à taxa de câmbio vigente, está em torno de US $\$ 320$ bilhões. Isso foi possível porque o dinheiro de fora que entrava na economia, formando reservas, foi "esterilizado" mediante a emissão de títulos públicos. Esse estoque crescente de papéis foi sendo engordado por taxas de juros reais, que, entre 1995 e 1998, ficaram na média em torno de $21 \%$ ao ano (Belluzzo, 2004, p. 2).

Alcançar superávit comercial em face de uma dívida externa em ascensão é como tratar um paciente que necessita de uma operação séria — talvez sem anestesia - com um remédio calmante para diminuir a dor e não para eliminá-la. A política econômica deve se direcionar para tratar as causas, e não as conseqüências do problema. Isso só pode acontecer se a dívida ex- 
terna (e os juros pagos sobre essa dívida) foi renegociada e solucionada de forma a permitir o crescimento econômico no país, sem implicar moratória. A economia não pode continuar trabalhando em função da dívida externa e das remessas de juros ao exterior.

\subsubsection{Atacar os spreads altos cobrados pelos bancos}

A principal medida a ser tomada nesse sentido é o governo rever a estrutura do mercado bancário através de atuação efetiva do Sistema Brasileiro de Defesa da Concorrência (SBDC). O Conselho Administrativo de Defesa Econômica (Cade), a Secretaria de Acompanhamento Econômico (SEAE) e a Secretaria de Direto Econômico (SDE) deveriam fiscalizar e colocar em prática a política de concorrência no setor financeiro com a finalidade de verificar o poder oligopolista dos bancos em cobrar taxas de juros que penalizam o consumo e o investimento e, por conseqüência, a taxa de crescimento do PIB. Senão, mantendo a taxa de juros Selic real em até $11 \%$ a.a. ou a sua redução em até $10 \%$ a.a., não terá efeito significativo sobre as taxas de juros praticados no setor privado.

\section{CONCLUSÃO}

O objetivo principal deste trabalho foi analisar o comportamento e os fatores determinantes das taxa de juros e seus efeitos sobre a condução da política macroeconômica no Brasil, no período de 1994 a agosto de 2004. Assim, tentou responder a quatro questões: As taxas de juros no Brasil são altas ou não? Quais são as forças determinantes das taxas de juros no Brasil? Quais são as implicações para a economia se essas taxas permanecerem altas? O que pode ser feito para reduzir as taxas de juros de seus níveis atuais? As seguintes conclusões a respeito podem ser feitas.

Primeiro, as taxas de juros praticadas no Brasil estão muito altas em comparação com aquelas praticadas no mercado internacional. Inclusive, dados mostram que uma aplicação no Brasil rende, em termos reais, 11 vezes mais do que uma aplicação no mercado internacional. No mercado interno, foi demonstrado que as taxas de juros praticadas nos empréstimos ao setor privado são abusivas e alcançaram três dígitos. Foi verificado, tam- 
bém, que o alto nível de spread cobrado pelos bancos é o fator principal por de trás de juros exorbitantes praticados na economia brasileira. A média da relação spread/taxa de captação para o setor privado foi de $183 \%$. O trabalho revela também quatro fatores-chave que oferecem explicação para a alta taxa de juros: estabilizar preços via contenção da demanda interna; garantir o financiamento do déficit em transações correntes; evitar ataques especulativos contra o câmbio, objetivos os quais não foram totalmente alcançados. Assim, enquanto a taxa de juros desempenhou papel importante em conter a inflação, não foi suficiente para garantir o financiamento para o setor externo e evitar o ataque especulativo contra o real que levou a crise cambial no começo de janeiro de 1999. Constatou-se, também, que o alto nível de spread cobrado pelos bancos é o fator principal por trás dos juros altíssimos praticados na economia brasileira.

Da mesma forma, verificou-se que uma das graves conseqüências das altas taxas de juros é o aumento da dívida pública. A relação dívida interna/ PIB, que era $30 \%$ em 1995, saltou para 52,4\% em abril de 2003. Como a dívida pública resulta do déficit orçamentário, foi demonstrado, também, que a carga de juros é o componente principal responsável pelo déficit orçamentário. Assim sendo, pode ser argumentado que o déficit orçamentário não foi causado por excesso de gastos com infra-estrutura ou outros gastos sociais, mas tem origem puramente financeira, e resultou diretamente da forma de manutenção da taxa de juros alta, que foi uma peça chave do programa da estabilização econômica. Em relação ao setor produtivo, as altas taxas de juros foram apontadas como principal entrave ao crescimento econômico.

Nesse sentido, para diminuir as taxas de juros de seus níveis atuais, foram sugeridas as seguintes medidas: a diminuição da razão dívida pública/PIB; uma política monetária expansionista e responsável; ataque aos spreads altos cobrados pelos bancos, através de maior fiscalização da política de concorrência no setor financeiro, e ao poder de monopólio dos bancos de cobrar taxas de juros que penalizam o consumo e o investimento e, por conseqüência, a taxa de crescimento do PIB. Finalmente, a diminuição das remessas de juros sobre a dívida externa, as quais só ocorrerão se a dívida externa for renegociada e selecionada de forma a permitir que o país volte a crescer. 


\section{NOTAS}

1. Existem no Brasil dois índices de preços utilizados como indexadores para o mercado financeiro: o Índice de Preços ao Consumidor - Mercado (IPC-M) e o Índice Geral de Preços do Mercado (IGP-M). Ambos são pesquisados pela FGV entre os dias 21 de um mês e 20 do seguinte, para serem divulgados antes do final do mês-calendário, a fim de utilização como referência financeira. A diferença entre eles reside na abrangência e na composição de cada um. O IPC-M é pesquisado nos Municípios do Rio de Janeiro e São Paulo. Os preços pesquisados pertencem a uma cesta de consumo de famílias com renda de até 33 salários mínimos. O IGP-M é pesquisado em todo o país e está estruturado para captar o movimento geral de preços com a finalidade de refletir, de forma adequada, as variações do poder de compra da moeda. Ele é calculado através de média ponderada do Índice de Preços por Atacado (IPA), Índice de Preços ao Consumidor (IPC) e Índice Nacional de Custo da Construção (INCC), com pesos iguais a 60\%, 30\% e 10\%, respectivamente. É utilizado principalmente para a comunidade financeira, reajustes de contratos e como indexador de tarifas públicas. Assim, o IGP-M foi utilizado como indexador neste trabalho pela sua abrangência, sua composição e sua utilização.

2. O leitor deve ter cautela em entender ou interpretar que a situação do fator trabalho melhorou após a implementação do Plano Real. Vale lembrar, nesse sentido, que, apesar de aumento dos salários reais nesse período, índices de IPEADATA mostram que os mesmos voltaram a cair após 1997. Além disso, no que se refere ao aspecto distributivo do Plano Real, aos dados publicados pelo IBGE e aos trabalhos feitos por Gonçalves e Pomar (2002) e Sant'Anna (2003), evidencia-se que a massa salarial (relação salário/PIB) vem declinando de aproximadamente 45,2\% do PIB em 1993 para alcançar quase 36,1\% do PIB em 2002. Isso implica que, além de que o aumento de salário real foi temporário, foi acompanhado por um declíno na participação de massa salarial na economia e, portanto, piorou o aspecto socioeconômico do fator trabalho.

\section{REFERÊNCIAS BIBLIOGRÁFICAS}

AFANASIEFF, T. S.; LHACER, P. M.; NAHANE, M. The determinents of bank interest spread in Brazil. Working Paper Series, n. 46, ago. 2002. Banco Central do Brasil.

BANCO CENTRAL DO BRASIL. Departamento de Estudos e Pesquisas. Juros e Spread Bancário no Brasil, nov. 1999. Disponível em: www.bcb.gov.br/ftp/juro-spread.pdf. Acesso em diversos dias em mar. e maio 2004.

Economia bancária e crédito: avaliação de um ano do projeto juros e spread bancário, nov. 2000. Disponível em: www.bcb.gov.br/ftp/jurospread112000.pdf. Acesso em diversos dias em mar. e maio de 2004.

Economia bancária e crédito: avaliação de 2 anos do projeto juros e spread bancário, nov. 2001. Disponível em: www.bcb.gov.br/ftp/jurospread112001.pdf. Acesso em diversos dias em mar. e maio de 2004. 
Economia bancária e crédito: avaliação de 3 anos do projeto juros e spread Bancário, nov. 2002. Disponível em: www.bcb.gov.br/ftp/jurospread112002.pdf. Acesso em diversos dias em mar. e maio de 2004.

Economia bancária e crédito: avaliação de 4 anos do projeto juros e spread bancário, dez. 2003. Disponível. em: www.bcb.gov.br/ftp_economia_bancaria_credito.pdf. Acesso em: 24 jul. 2004. 2004

BANK FOR INTERNATIONAL SETTLEMENTS. Recent Innovations in International Banking. Basle: BIS, 1986.

BAUMANN, R.; CANUTO, O.; GONÇALVES, R. Economia Internacional. São Paulo: Campus, 2004.

BELLUZZO, L. G. Lições Contemporâneas: desajuste fiscal e abertura financeira. Folha de S. Paulo, Folha Dinheiro. São Paulo, 26 set. 2004.

CARAMAZZA, F.; JAHANGIR A. Fixed or flexible? Getting the exchange rate right in the 1990s. Economic Issues, IMF, n. 13. 1998.

CINTRA, M. Juros, culpa de quem? Conjuntura Econômica, Rio de Janeiro: FGV, n. 6, jun. 2005.

; ETLIN, M. Its the spread, stupid. Conjuntura Econômica, Rio de Janeiro: FGV, jul. 2003.

CLARICE M. A taxa de juros básica e a economia real. Conjuntura Econômica, Rio de Janeiro: FGV, n. 6, jun. 2003.

CONJUNTURA ECONÔMICA. Rio de Janeiro: FGV, n. 5, maio 2004.

, Rio de Janeiro: FGV, n. 11, nov. 2004.

DORNBUSCH, R.; FISCHER, S. Introdução a macroeconomia. São Paulo: Mcgraw-Hill, 1993.

EUROPEAN CENTRAL BANK. Monetary Financial Institutions (MFI) interest rates. Disponível em: www.ecb.int/press/pr/stats/mfi/html/index.em.html. Acesso em: 14 out. 2004.

GARCIA, M. G. P. Public debt management, monetary policy and financial institutions. Texto para Discussão, Departamento de Economia. Rio de Janeiro: PUC, n. 464, jun. 2002.

GHOSH, A. R.; Jonathan D. O.; Anne-Marie G.; Holger C. W. Does the exchange rate regime matter for inflation and growth. Economic Issues, IMF, n. 2, 1997.

GLOBAL INVEST. Principais indicadores macroeconômicos do Brasil 2000-2005 e cenário base 2005. Disponível em: http://www.globalinvest.com.br/relatorios/proj_mar05.pdf. Acesso em 17/05/05.

GONÇALVES, R.; POMAR, V. A armadilha da dívida: como a dívida pública interna impede o desenvolvimento econômico e aumenta a desigualdade social. São Paulo: Fundação Perseu Abrão, 2002.

HALL, R.; MARC, L. Macroeconomia: princípios e aplicações. São Paulo: Thompson, 2003.

IMF. International Financial Statistics, dez. 2001. 
IPEA. Boletim de Conjuntura. (Vários números). Disponível em: www.ipeadata.gov.br. Acesso em diversos dias em mar e jun. 2004.

Boletim de Conjuntura, n. 68, 2005. Disponível em: www.ipeadata.gov.br. Acesso 18 maio 2005.

IPEADATA. Instituto de Pesquisas Econômicas Aplicadas. Disponível em: www.ipeadata.gov. br. Acesso em diversos dias em mar. e jun. 2004.

KEYNES, J. M. Teoria geral do emprego, do juro e do dinheiro. São Paulo: Abril Cultural, 1983.

LIBSEY, R. Global Imbalances and American Trade Policy. Atlantic Economic Journal, 16 jun. 1988. p. 1-11.

CINTRA M.; ETLIN, M. It's the Spread, Stupid. Conjuntura Econômica, Rio de Janeiro: FGV, n. 7, jul. 2003.

MATTOSO, J.; BALTAR, P. Estrutura econômica e emprego no Brasil: a experiência recente. In: REIS VELlOSO, J. (Org.). Brasil: desafios de um país em transformação. Rio de Janeiro: J. Olímpio, 1997, p. 294-314.

MESSER, C. A taxa de juros básica e a economia real. Conjuntura Econômica, Rio de Janeiro: FGV, n. 6, jun. 2003.

MUNDELL, R. Capital mobility and stabilization policy under fixed and flexible exchange rates Canadian. Journal of Economics and Political Science, p. 475-485, nov. 1963.

NAKANE, M. I. Concorrência e spread bancário: uma revisão da evidência para o Brasil. In: BANCO CENTRAL DO BRASIL (2003): Economia bancária e crédito: avaliação de 4 anos do projeto Juros e spread bancário. Disponível em: www.bcb.gov.br/ftp_economia_bancaria_credito.pdf. Acesso em: 28 jul. 2004.

NAKANO, Y. Há muito espaço para a queda dos juros. Conjuntura Econômica, Rio de Janeiro: FGV, n. 9, set. 2004.

PATINKIN, D. Money, Interest and Prices. 2nd ed. Nova York: Harper \& Row, 1965.

PIGOU, A. C. Employment and Equilibrium. Londres, 1941. Apud ACKLY, G. Teoria Macroeconômica. São Paulo: Pioneira, 1969.

RIMA, I. História do pensamento econômico. São Paulo: Atlas, 1990.

SANT'ANNA, A. A. A distribuição funcional da renda e crescimento econômico: uma análise para a década de noventa. (Dissertação de Mestrado) - Instituto de Economia, Universidade Federal do Rio de Janeiro, 2003.

TONOOKA, E. K.; KOYAMA, S. M. Taxa de juros e concentração bancária no Brasil. Trabalhos para Discussão do Banco Central do Brasil, n. 62, 2003.

WYPLOZ, C. Globalized Financial Markets and Financial Crises. Paper presented at the conference on "Coping with Financial Crises in Developing and Transition Countries" organized by the forum on Debt and Development in Amsterdam, mar. 16-17, 1998. 